\title{
Efficacy of a novel, biologically active food supplement in type 2 diabetes mellitus: a patient-blinded, prospective, clinical trial
}

This article was published in the following Dove Press journal:

Nutrition and Dietary Supplements

8 April 201I

Number of times this article has been viewed

\section{Vinod K Podichetty' \\ Mishel Weshler ${ }^{2}$ \\ John Schlosser ${ }^{3}$}

'Research Practice Partners Inc., Miramar, Florida, USA; ${ }^{2}$ Weshler and Weshler Clinic, Nazareth Illit, Israel; ${ }^{3}$ Rockland Endocrine and Diabetic Services, Suffern, New York, USA
Correspondence: Vinod K Podichetty Research Practice Partners Inc., 3350 SW I 48 Ave., Miramar, FL 33027, USA

$\mathrm{Tel}+\mathrm{I} 95455942$ I3

Fax +I 9544166506

Emailvp@rppmed.com
Abstract: Despite significant achievements in the prevention and management of diabetes, its prevalence has risen exponentially, creating a paramount need for alternative therapies. The purpose of the study was to investigate the safety and efficacy of two novel, biologically active supplements (fenugreek, fennel, sage, olive, and cinnamon and other ingredients) in decreasing blood glucose levels (BGLs) in type 2 diabetes mellitus (T2DM). Between June 2008 and July 2009, 154 patients were screened for T2DM and inadequate glycemic control. Fifty-one subjects meeting inclusion/exclusion criteria were enrolled in a prospective clinical study. All patients $(n=51)$ were studied for 24 weeks ( 6 months), the first 3 weeks being the placebo phase, followed by 14 weeks of active supplement use and observation for 3 weeks. Patients returned to active supplement use for an additional 3 weeks. All participants were tested for fasting BGL once every week during a 22-week period. The average age of the subjects was 52.6 years (23 male; 28 female), and average reference BGL (on day 1) was $265.7 \mathrm{mg}$ / dL. During the first 3-week placebo period, patients showed no detectable change in BGL. At week 10 (after 7 weeks of supplement use), BGL was reduced by 47\% compared with baseline (mean + standard deviation, day 1 vs week 10, $265.7+86.2$ vs $131.6+31.7$; paired $t$-test $=-11.8, P<0.001)$, and at week 17 , BGL decreased by $59 \%(P<0.001)$. Between weeks 18 and 20, during which no participant received placebo or supplements, BGL did not decrease. The glucose-lowering effect of the supplement was stable and prolonged to maintain BGL at a constant level. Patients reported satisfaction on a Likert scale, and no side effects were reported during the course of the study. The current study indicates that the new biologically active dietary supplements were effective in decreasing BGL in T2DM patients with no side effects and has therapeutic promise in regulating BGL.

Keywords: blood glucose, cinnamon, fenugreek, glucose metabolism, olive, sage, type 2 diabetes mellitus

\section{Introduction}

The growing prevalence of obesity and a sedentary lifestyle are the key underlying causes for type 2 diabetes mellitus (T2DM) becoming a global public health problem and imposing a high financial burden on health care costs. ${ }^{1-4}$ The rising epidemic of T2DM reflects the profound changes in society and in behavioral patterns of the population over recent decades. Although genetic make-up is important in determining a person's susceptibility to diabetes, societal changes and worldwide high-caloric nutrition transition are driving the diabetes epidemic. Although new research in medications is leading the way toward better therapies and can be an important part of the treatment plan, common drugs, such as antidiabetics like sulfonylureas, meglitinides, biguanides, thiazolidinediones, $\alpha$-glucosidase inhibitors and glucagon-like peptide-1 
agonists, and dipeptidyl peptidase-4 inhibitors, are limited by drug interactions, associated side effects with long-term complications, and the high cost of prescription drugs. ${ }^{5}$

Balanced modulation of several targets in the treatment of diabetes can provide superior therapeutic outcome with decreased side effects compared with the action of a single selective ligand. ${ }^{6}$ In order to hit the multiple targets implicated in complex clinical disorders such as diabetes, two strategies have been proposed. The first attempts to employ a single compound to hit multiple targets. The second is the use of multiple active ingredients in one preparation. ${ }^{6-8}$ Although this premise has become a common feature in the drug development process, its principal applicability in developing nutritional supplements is still primitive. A unique novel combination of Trigonella foenum-graecum (fenugreek), Foeniculum vulgare (fennel), Salvia officinalis (sage), Olea europea (olive), cinnamon, and Silybum marianum and other ingredients with high insulinotrophic properties holds great promise in this direction, influencing multiple biological activities with significant physiological effects. 4-hydroxyisoleucine (4-OH-Ile), an amino acid extracted and purified from fenugreek seeds, which is the main component of such preparations, has been found to display an insulinotropic activity in vitro because its stimulating effect is clearly related to the augmentation of glucose concentration. ${ }^{9}$ Such a glucose dependency is not shared by sulfonylureas, ${ }^{10}$ the only insulinotropic drug currently used to treat T2DM, and, as a consequence, hypoglycemia remains a frequent undesirable side effect of sulfonylurea management. ${ }^{11,12}$ Consequently, 4-OH-Ile, which is found only in plants, due to its particular insulinotropic action, ${ }^{9}$ may be considered a novel secretagog to trigger insulin release. This action brings immense value in the treatment of T2DM, a condition characterized by defective insulin secretion associated with various degrees of insulin resistance. ${ }^{13-16}$

However, current studies offer limited clinical evidence about the role of these biologically active compounds in glucose homeostasis and insulin sensitivity. The purpose of the study is to clinically examine the effect of these biologically active food supplements (Sugar Crush, NaturEra LLC, Israel) by investigating the efficacy in decreasing blood glucose level (BGL) in patients with T2DM.

\section{Materials and methods}

\section{Plant materials and preparation of extract}

Proprietary liquid formulations containing six active key ingredients, i) Trigonella foenum-graecum, ii) Foeniculum vulgare, iii) Salvia officinalis, iv) Olea europea, v) cinnamon, and vi) Silybum marianum, with minor quantities of secondary elements, was developed in the laboratory and then adapted for production in a commercial manufacturing facility. The formula was carefully constructed with standard quality control measures applied throughout the preparation process. All ingredients required for the preparation were obtained from a certified local commercial source in Israel. Samples of the ingredients were sent to the laboratory for testing prior to release for production. All solid forms were grounded to a fine powder in a mixer under chilled conditions, suspended, and filtered. Each ingredient was placed in a drum for 21 days for extracting proposes, during which period the ingredient was mixed with organic alcohol and purified water. Weighed amounts of individual ingredients were distilled in separate containers and later mixed in proportions with the required amounts of water and surface sterilization. Water was added while stirring with constantly maintained $\mathrm{pH}$ adjustments. At the end of 21 days, the extract was checked and mixed with the rest of the ingredients under a proprietary formulation to achieve accurate proportions. A dispersing agent was added to the concentrated active ingredient extract to prevent clumping and aggregation of individual components. The dialyzed extract was aliquoted and stored at predetermined temperatures. Advanced manufacturing processes for in situ conversion and incorporation of the concentrated compounds into a sustained-release therapeutic liquid dosage form were established. The process was carefully tested to provide an efficient and reproducible method to manufacture a liquid supplement with active ingredients. The entire process facilitated a sustained release of the biologically active food supplement over prolonged intervals of time, thereby improving efficacy and patient satisfaction. Caution was executed to obtain a homogenous preparation that did not separate on standing. The final product was packaged in sterilized bottles, each measuring $125 \mathrm{~mL}$ for the study purpose. No refrigeration was required for storage of the bottled preparation at any time.

\section{Patients}

Between June 2008 and July 2009, 154 patients were screened for T2DM and a history of poor glycemic control. Only patients meeting inclusion/exclusion criteria were enrolled in the prospective clinical study. Fifty-one subjects (23 males and 28 females) between the ages of 18 and 70 years who were undergoing a diet treatment only, who had been diagnosed with T2DM, and who were not pregnant or nursing a child formed the study sample. Subjects with consistent glucose levels documented by previous medical 
test records on diet treatment only were selected for study. Other exclusion criteria were i) patients taking medications such as systemic glucocorticoids, which can affect blood sugar levels; ii) any chronic medications that did not have a stable dose for at least 3 months prior to entering the study; iii) severe hypoglycemia (less than $50 \mathrm{mg} \%$ ); and iv) any hypoglycemic event requiring intravenous glucose infusion. Approximately $70 \%$ of the patients were responders to the advertisement of the newsletter from the investigator, and the rest were referred by community physicians. The study was closed for participation in July 2009. Figure 1 demonstrates the participant flow chart. Written informed consent was obtained from each patient before the initiation of the study.

Patients were sequentially enrolled and assigned a randomized number by the investigator if they met the inclusion criteria. All participants had an initial screening visit where they completed a generic health questionnaire, and their medical history was reviewed by the study investigator prior to enrolment. Concurrent lipid-lowering, antihypertensive medications were allowed for study purposes. The study was conducted in four phases during a total 24-week period (6 months) (Figure 1). All patients received a placebo for the first 3 weeks of the study (placebo phase) followed by an active dose of the investigational supplement up until week 17 (supplement phase). Between week 18 and week 20, no study supplement was given, followed again by an active dose of the supplement until week 23. The last week of the study was utilized to follow up on patient data. All active supplement and placebo were supplied by the manufacturer in a liquid form in prelabeled, bottled containers. The study participants were blinded to the study treatment during the entire 24 -week period until after the completion of the study and final data review, except in cases of an emergency.

\section{Measurements and assessment}

Fasting blood samples $(5 \mathrm{~mL})$ were collected from all patients, and serum was analyzed for glucose by spectrophotometric assays on automated clinical chemistry analyzer Dimension ${ }^{\circledR}$ RxL (Dade Behring, Newark, NJ, USA). Fresh, clear, unhemolyzed serum was collected as the specimen with the patient fasting for 12 hours prior to specimen collection. All laboratory collection was performed by a trained laboratory technician using a standard venipuncture tube to draw the patient sample. Subject weights and fasting BGL were measured on the first day of the study and every week thereafter. Fasting was defined as no caloric intake for at least 8 hours before testing. Subjects were scheduled on a Monday, Wednesday, or Friday and measured between 9.00 a.m. and 11.00 a.m. after meals, in order to maintain constant and reliable measurement interval.

The glucose-lowering effect of the supplement was measured by comparing BGLs tested on initiation of the study (day 1), during placebo treatment (week 1 to week 3 ),

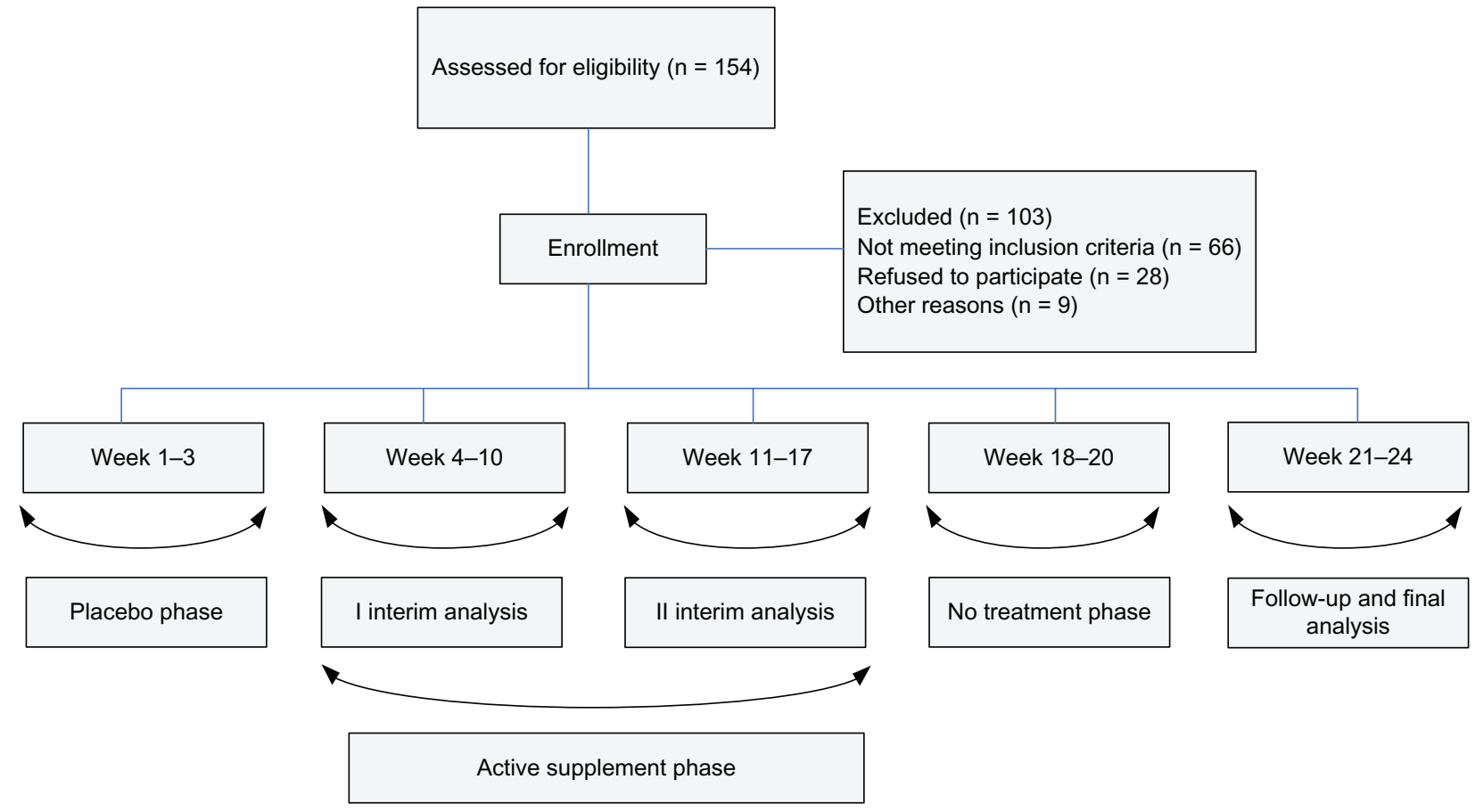

Figure I Participant flow chart and study design. 
treatment with the supplement (week 4 to week 17), and no treatment period (week 18 to week 20) and comparing baseline data with data at the end of the study. All patients were assessed using the following efficacy parameters: i) reduction in fasting BGL and ii) patient satisfaction measured to demonstrate symptom change and approval of the formulation using a 6-item Likert scale.

\section{Treatment satisfaction}

Patients were asked three questions regarding their satisfaction with treatment at week 22 using a Likert scale, which is a commonly used psychometric scale used in questionnaires. The first item asked patients how satisfied they were with their treatment in reducing measureable BGL, with responses based on a 6-point scale, ranging from "very satisfied" to "very dissatisfied". A second item asked patients whether they would recommend their nutritional supplement treatment to a friend with similar health problems. The response scale ranged between "definitely yes", "probably yes", "probably not", and "definitely not". The third item asked patients how effective their treatment was in eliminating their symptoms (measured clinically as excessive thirst, frequent urination, and fatigue), with response options ranging from "very effective, relieved all of my symptoms" to "very ineffective, did not relieve or lessen my symptoms".

\section{Dose}

Two forms of nutritional supplements were provided for the study purposes: a more potent formulation, Sugar Crush, which was intended for consumption during meals for the first 12 weeks only; and a complimentary maintenance formula variety, Sugar Crush Daily, which was intended for consumption in conjunction with the potent formulation for the first 12 weeks and then on its own for an additional 10 weeks of the study. Depending on the patients' use of concurrent medication for blood pressure and or cholesterol and the patients' weight, two dose forms were employed. Tables 1 and 2 demonstrate dose instructions for patients enrolled in the study. This dose protocol was developed to adjust for overweight individuals, due to the strong association that exists between these patients and T2DM than for normal weight individuals. ${ }^{17,18}$
It was important to factor these considerations in developing treatment regimens for complex metabolic conditions such as T2DM.

\section{Statistical analysis}

We used SAS ${ }^{\circledR}$ statistical software (Version 9; SAS institute, Cary, NC, USA) for all statistical analysis. All the data were compared with regard to the measurements of each parameter taken at each week before and after the use of the active supplement. Paired Student's $t$-test was used for statistical analysis, and all data were expressed as mean $(\mathrm{M}) \pm$ standard deviation (SD). A $P$ value of less than 0.05 was considered indicative of statistical significance for the pilot nature of the study.

\section{Results}

A 22-week prospective pilot study of a fenugreek-based liquid formulation was performed in patients with T2DM. The demographic results of the study population are summarized in Table 3. A total of 23 participants were men and 28 were women, with an average age of 52.6 years (range 28-79 years). Two patients who dropped out of the study for travel reasons were not included in the analysis. Estimated duration of diabetes was $4.8 \pm 0.5$ years, and body mass index was $32.3 \pm 4.0 \mathrm{~kg} / \mathrm{m}^{2}$. Nine of the patients had hypertension, defined as blood pressure of $140 \mathrm{~mm} \mathrm{Hg}$ and/or $90 \mathrm{~mm} \mathrm{Hg}$ or over, being treated by antihypertensive agents. There were 10 cases of hyperlipidemia, defined as total cholesterol of $220 \mathrm{mg} / \mathrm{dL}$ or over and/or total triglyceride of $150 \mathrm{mg} / \mathrm{dL}$ or over. In addition, there were two cases of hyperuricemia. Fifteen patients $(29.4 \%)$ were being treated by diet therapy alone, six patients by a $\alpha$-glucosidase inhibitor, six patients by a sulfonylurea, three patients by nateglinide, and 21 patients (41\%) by a biguanaide.

Table 4 gives the fasting BGL in the sample population of the study. The efficacy of the study nutritional supplement showed a continued and significant decrease in BGLs during a 22 -week period. This was in alignment with the trend line plotted from our unpublished anecdotal data (Figure 2). The mean initial fasting level was high $(265.8 \mathrm{mg} / \mathrm{dL})$ compared with desirable values for fasting BGL $(70-110 \mathrm{mg} / \mathrm{dL}) .{ }^{19}$ During the first 3 weeks of the study (placebo phase), all

Table I Dose directions for diabetics not using blood pressure or cholesterol medications

\begin{tabular}{|c|c|c|}
\hline \multirow[t]{2}{*}{ Supplement } & \multicolumn{2}{|l|}{ Weight of person } \\
\hline & Under 220 lbs & Over 220 lbs \\
\hline Sugar Crush just before or during breakfast & $2.5 \mathrm{~mL}$ along with or followed by 6 oz of water & $5 \mathrm{~mL}$ along with or followed by $6 \mathrm{oz}$ of water \\
\hline Sugar Crush just before or during dinner & $2.5 \mathrm{~mL}$ along with or followed by $6 \mathrm{oz}$ of water & $5 \mathrm{~mL}$ along with or followed by $6 \mathrm{oz}$ of water \\
\hline Sugar Crush Daily just before or during lunch & $2.5 \mathrm{~mL}$ along with or followed by $6 \mathrm{oz}$ of water & $5 \mathrm{~mL}$ along with or followed by $6 \mathrm{oz}$ of water \\
\hline Sugar Crush Daily just before bedtime & $2.5 \mathrm{~mL}$ along with or followed by $6 \mathrm{oz}$ of water & $5 \mathrm{~mL}$ along with or followed by $6 \mathrm{oz}$ of water \\
\hline
\end{tabular}


Table 2 Dose directions for diabetics using blood pressure or cholesterol medications

\begin{tabular}{|c|c|c|}
\hline \multirow[t]{2}{*}{ Supplement } & \multicolumn{2}{|l|}{ Weight of person } \\
\hline & Under 220 lbs & Over 220 lbs \\
\hline No supplement use & $\begin{array}{l}\text { Morning is reserved for blood pressure or cholesterol medication. } \\
\text { Do not use Sugar Crush within } 2 \text { or } 3 \text { hours of medications }\end{array}$ & $\begin{array}{l}\text { Morning is reserved for blood pressure or } \\
\text { cholesterol medication. Do not use Sugar } \\
\text { Crush within } 2 \text { or } 3 \text { hours of medications }\end{array}$ \\
\hline $\begin{array}{l}\text { Sugar Crush Daily just } \\
\text { before or during lunch }\end{array}$ & $\begin{array}{l}2.5 \mathrm{~mL} \text { along with or followed by } 6 \mathrm{oz} \text { of water but no earlier than } \\
2-3 \text { hours after blood pressure or cholesterol medication }\end{array}$ & $\begin{array}{l}5 \mathrm{~mL} \text { along with or followed by } 6 \text { oz of water } \\
\text { but no earlier than } 2-3 \text { hours after blood } \\
\text { pressure or cholesterol medication }\end{array}$ \\
\hline $\begin{array}{l}\text { Sugar Crush just before } \\
\text { or during dinner }\end{array}$ & $\begin{array}{l}5 \mathrm{~mL} \text { along with or followed by } 6 \text { oz of water but no earlier than } \\
2-3 \text { hours after blood pressure or cholesterol medication }\end{array}$ & $\begin{array}{l}7.5 \mathrm{~mL} \text { along with or followed by } 6 \mathrm{oz} \text { of } \\
\text { water but no earlier than } 2-3 \text { hours after } \\
\text { blood pressure or cholesterol medication }\end{array}$ \\
\hline $\begin{array}{l}\text { Sugar Crush Daily just } \\
\text { before bedtime }\end{array}$ & $\begin{array}{l}2.5 \mathrm{~mL} \text { along with or followed by } 6 \mathrm{oz} \text { of water only if } \\
\text { experiencing unusually high glucose levels. If levels are not } \\
\text { unusually high, do not use product before bedtime }\end{array}$ & $\begin{array}{l}5 \mathrm{~mL} \text { along with or followed by } 6 \text { oz of water } \\
\text { but no earlier than } 2-3 \text { hours after blood } \\
\text { pressure or cholesterol medication }\end{array}$ \\
\hline
\end{tabular}

participants were acting as their self-controls and were followed during this period without any dietary counseling and/or nutritional intervention except the standard recommendations by the treating physician. There was a mild increase of $8.7 \%$ in BGL during this period. Between week 1 and week 10, when the first interim analysis was performed, the mean fasting BGL decreased significantly by $46.7 \%$ (paired $t$-test statistic $=-11.8, P<0.001)$. This phase included supplementation with a $2.5 \mathrm{~mL}$ dose of active formulation as directed, depending on the subject's current use of blood pressure and/or cholesterol medications and weight. After the completion of 17 weeks of the study (3 weeks of placebo use and 14 weeks of active supplement use), fasting BGL decreased by a mean of $59 \%(P<0.001)$, demonstrating continued efficacy of the nutritional supplement on glucose metabolism. There was a moderate leveling of glucose levels at the end of a 3-week period (between week 18 and week 20) where patients received no supplement treatment (mean BGL change $=22.4 \%$ ), with scaling down BGL again upon supplement reinitiation. Overall, at the conclusion of the study after 22 weeks, the average BGL demonstrated a statistically significant reduction by $58.5 \%$ (paired $t$-test statistic $=-14.7, P<0.001)$ (Figure 3$)$. Comparison of

Table 3 Demographic characteristics of the study sample

\begin{tabular}{ll}
\hline Characteristic & Data value (SD) \\
\hline Total sample $(\mathrm{n})$ & $5 \mathrm{I}$ \\
Gender & \\
$\quad$ Male & 23 \\
$\quad$ Female & 28 \\
Age (in years) & $52.6(12)$; range $=28-75$ \\
Weight $(\mathrm{kg})$ & $171.2(77.6)$ \\
Body mass index $\left(\mathrm{kg} / \mathrm{m}^{2}\right)$ & $32.3(4.0)$ \\
Duration of diabetes (in years) & $4.8(0.5)$ \\
\hline
\end{tabular}

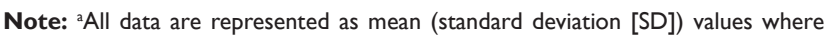
indicated.
BGL and corresponding change at different time intervals is demonstrated in Tables 5 and 6 . No side effects were reported by any patient at the end of the study.

In respect of determining satisfaction with the treatment using the Likert scale, $94 \%$ of the patients were satisfied, which corresponded to their reduced BGL. Statistically significant differences in scores were observed between those who indicated that they would recommend the treatment to a friend compared with those who would not $(P<0.001)$.

\section{Discussion}

An exponential rise in worldwide cases of disorders of glucose and insulin metabolism, overweight, mild dyslipidemia, and hypertension has led to the enormous problem of T2DM. Trigonella foenum-graecum appears to exhibit a range of actions of potential benefit to control glucose metabolism in diabetes. In the present study, the effects on glucose metabolism of a combination of organic herbal products with fenugreek as the key ingredient were evaluated.

An active component of fenugreek seeds has been found to be associated with a defatted fraction that is rich in fiber-containing steroidal saponins and proteins. ${ }^{20}$ Sauvaire et $\mathrm{a}^{9}$ have demonstrated a novel amino acid derivative, 4-hydroxyisoleucine, which is also extracted from fenugreek seeds, that stimulates glucose-dependent insulin secretion from isolated rat and human islets. ${ }^{8}$ Additionally, fenugreek acts by delaying glucose absorption and enhancing its utilization in noninsulin-dependent diabetic patients. ${ }^{21}$ All other ingredients have also been extensively documented in the literature to improve glucose and lipids in subjects with T2DM. ${ }^{22,23}$ Foeniculum vulgare is a widely used traditional medicinal plant for its antibacterial potential. ${ }^{24}$ Common sage (Salvia officinalis) is among the plants that are claimed to be beneficial to diabetic patients, and 
Table 4 Effect of supplement use by diabetic subjects at different time points compared with baseline

\begin{tabular}{|c|c|c|c|c|c|}
\hline Time point $\mathrm{t}^{\mathrm{a}}$ & Mean blood glucose level (SD) & Minimum & Maximum & Mean \% change & $P$ value \\
\hline Baseline & $265.7 \pm 86.2$ & 129.0 & 477.0 & $10.9 \%$ & $0.003^{b}$ \\
\hline Week 3 & $288.9 \pm 90.0$ & 125.0 & 471.0 & & \\
\hline Baseline & $265.7 \pm 86.2$ & 129.0 & 477.0 & $-59.0 \%$ & $<0.001$ \\
\hline Week 17 & $102.0 \pm 24.9$ & 74.0 & 165.0 & & \\
\hline Baseline & $265.7 \pm 86.2$ & 129.0 & 477.0 & $-58.5 \%$ & $<0.001$ \\
\hline Week 22 & $102.6 \pm 22.5$ & 76.0 & 158.0 & & \\
\hline
\end{tabular}

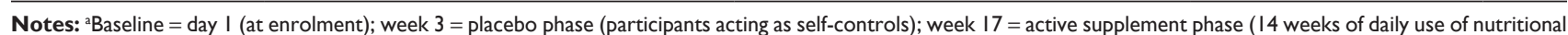

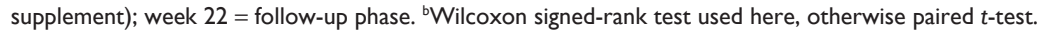

previous studies have suggested that some of its extracts have hypoglycemic effects in normal and diabetic animals. ${ }^{25}$ Sage has a high essential oil content that has also been tested and proved to be hypoglycemically active in diabetic rats. ${ }^{26-28}$ Similarly, aqueous extracts from cinnamon have been shown to increase in vitro glucose uptake and glycogen synthesis and to increase phosphorylation of the insulin receptor; in addition, cinnamon extract likely aids in triggering the insulin cascade system. ${ }^{29,30}$

Our findings coincide with those of earlier studies that reported that fenugreek in the diet reduced plasma glucose in diabetic human subjects. ${ }^{31,32}$ When using ancillary measures as benchmarks for patient improvement, the Likert satisfaction scale was able to demonstrate levels of change in patient-reported overall treatment effect and satisfaction. Similarly, in respect of overall treatment effect and recommending the treatment to a friend, the nutritional supplement was able to demonstrate significantly greater improvements in $>90 \%$ of the participants.

Medical conditions that require strict control of nutrient intake may be facilitated greatly by the use of a liquid formula diet, regular food, and additional nutritional supplementation such as the current investigational product. Calorie-controlled portions can be useful for controlling calories and initiating weight loss. Although not clinically tested, liquid formulations seem to boast faster absorption rates than pill supplements.

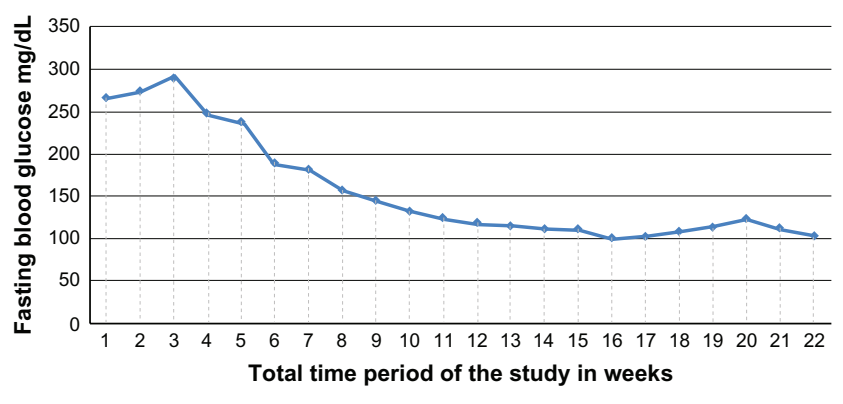

Figure 2 Effect on blood glucose in patients after active nutritional supplement use.
Pill supplements often contain soluble excipients as a binder to help hold the tablet together and give it strength and to improve the dissolution of poorly soluble ingredients. ${ }^{33}$ A wide variety of binders may be used, including lactose, dibasic calcium phosphate, sucrose, corn (maize) starch, and microcrystalline cellulose. However, in a diseased condition, the binding ingredients may make absorption slower and more difficult. Conversely, we hypothesize that liquid forms may begin being absorbed through the buccal mucosa rather than being slowly broken down in the digestive track. Although there are limited data, one disadvantage with liquid formulations is that they tend to expire much faster than pill forms. It is important to note here that the current supplement of investigation has a shelf life of 2 years.

Our study had several limitations. Data on types of foods consumed during the course of the study and frequency categories were not monitored. A concurrent double-blinded placebo control in our study was lacking. When people are newly diagnosed with diabetes, it is rational for them to improve their diet and exercise habits substantially. It is not clear to what extent this phenomenon may have influenced the results in our study. However, our data can be considered reliable, because participants were reminded weekly by telephone calls of having to follow a controlled diet and not use other supplements or drugs during the course of the study period. The study medication was not blinded to investigators, and

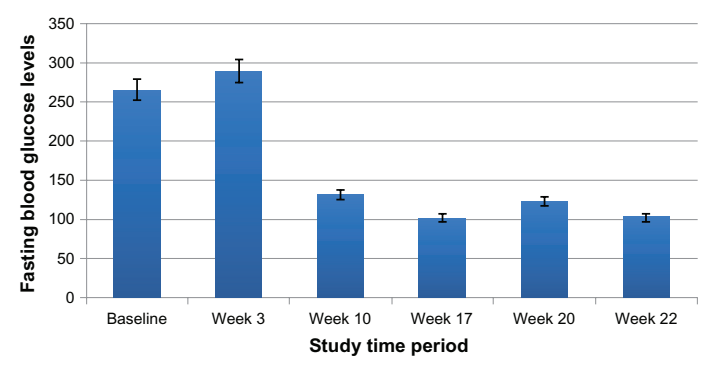

Figure 3 Effect on blood glucose in patients from baseline to the conclusion of the study at 22 weeks. 
Table 5 Effect of supplement use in diabetic subjects demonstrating sustained efficacy after a 3-week "nonuse" phase

\begin{tabular}{lllll}
\hline $\begin{array}{l}\text { Time } \\
\text { point }^{\text {a }}\end{array}$ & $\begin{array}{l}\text { Mean blood } \\
\text { glucose level (SD) }\end{array}$ & Minimum & Maximum & $\begin{array}{l}\text { Mean \% } \\
\text { change }\end{array}$ \\
\hline Week 17 & $102.0 \pm 24.9$ & 74.0 & 165.0 & $-59.0 \%$ \\
Week 20 & $123.2 \pm 39.2$ & 80.0 & 243.0 & $-50.6 \%$ \\
\hline
\end{tabular}

Notes: aWeek 17 = active supplement phase (14 weeks of daily use of nutritional supplement); week $20=3$ weeks of supplement discontinuation.

BGL was examined weekly, not daily. The majority of the improvement in glycemic control was conserved during a 3-week hiatus in treatment, which was unexpected with no clear explanation. One potential reason could be the retention of fat-soluble active ingredients in tissue and improved $\beta$ cell function owing to sustained normoglycemia. But it is difficult to make any such claims using the current study data. The study was also limited in terms of follow-up, as the beneficial effects of the investigational supplement need to demonstrate efficacy of periods longer than 22 weeks. It is also important to show that efficacy could be better under a $100 \%$ diabetic diet regimen. Evidence that the supplement resulted in decreased glycosylated hemoglobin A1C levels in the blood and other markers was not undertaken under the current investigational plan. The study would have been more informative if we had included glycated $\mathrm{Hb}$ measurements. The small sample size chosen based on pilot data may have been insufficient for a rigorous statistical analysis to demonstrate a clinically significant difference. Although an oral glucose tolerance test is more sensitive and modestly more specific than the fasting BGL to diagnose and detect diabetes, it is poorly reproducible and difficult to perform in practice. Because of ease of use, acceptability to patients, and lower cost, BGL was used in this study as the preferred diagnostic test. ${ }^{19}$ From a scientific standpoint, although the results could have been more illuminating by providing information on the 4-hydroxyisoleucine content of Sugar Crush or the content of other putative active ingredients, these were intentionally omitted due to proprietary rights. Assessment of liver or kidney function tests after supplement use was not performed as part of the study. Patients were only clinically monitored, and no side effects were reported in any patient at the end of the study. In an effort to address these limitations, the authors are undertaking a double-blind trial of this product to confirm and validate these results in a controlled protocol environment.

Nevertheless, the biological effect of food supplements with the right blend of ingredients prepared in a precise proportion not only allows for patients' meal individualization but also fulfills the deficit of much-needed biologically active components. Naturally occurring ingredients in our test product appear to aid in the normalization of carbohydrate metabolism with a beneficial effect and aid in improved quality of life in T2DM patients.

Table 6 Comparison of blood glucose level and corresponding change at different time intervals in diabetic study subjects after administration of active nutritional supplement

\begin{tabular}{|c|c|c|c|c|c|c|}
\hline Variable & $\mathbf{N}$ & Mean & Standard deviation & Median & Minimum & Maximum \\
\hline \multicolumn{7}{|c|}{ Paired $t$-test statistic $=-I I .8, P<0.00 I$} \\
\hline Baseline & 51 & 265.7 & 86.2 & 255.0 & 129.0 & 477.0 \\
\hline Week 10 & 51 & 31.6 & 31.7 & 128.0 & 76.0 & 202.0 \\
\hline Change & 51 & -134.1 & 80.9 & $-1 \mid 4.0$ & -364.0 & 19.0 \\
\hline$\%$ change & 51 & -46.7 & 17.4 & -48.3 & -80.2 & 11.9 \\
\hline \multicolumn{7}{|c|}{ Paired $t$-test statistic $=-|4.9, P<0.00|$} \\
\hline Baseline & 51 & 265.7 & 86.2 & 255.0 & 129.0 & 477.0 \\
\hline Week 17 & 51 & 102.0 & 24.9 & 94.0 & 74.0 & 165.0 \\
\hline Change & 51 & -163.8 & 78.5 & -154.0 & -384.0 & -39.0 \\
\hline \% change & 51 & -59.0 & 11.8 & -59.1 & -82.8 & -29.3 \\
\hline \multicolumn{7}{|c|}{ Paired $t$-test statistic $=-14.7, P<0.00$} \\
\hline Baseline & 51 & 265.7 & 86.2 & 255.0 & 129.0 & 477.0 \\
\hline Week 22 & 51 & 102.6 & 22.5 & 97.0 & 76.0 & 158.0 \\
\hline Change & 51 & -163.2 & 79.1 & -150.0 & -392.0 & -40.0 \\
\hline$\%$ change & 51 & -46.7 & 17.4 & -48.3 & -80.2 & 11.9 \\
\hline \multicolumn{7}{|c|}{ Paired $t$-test statistic $=4.6, P<0.0$} \\
\hline Week I7 & 51 & 102.0 & 24.9 & 94.0 & 74.0 & 165.0 \\
\hline Week 20 & 51 & 123.2 & 39.2 & 112.0 & 80.0 & 243.0 \\
\hline Change & 51 & 21.2 & 32.6 & 14.0 & -32.0 & 131.0 \\
\hline$\%$ change & 51 & 22.4 & 32.3 & 14.9 & -19.4 & 135.1 \\
\hline
\end{tabular}




\section{Conclusion}

Environmental factors have been implicated in the pathogenesis of T2DM both as triggers and potentiators of $\beta$-cell destruction, ${ }^{1-3}$ although the contribution of any individual exogenous factor has not yet been definitely proven. The present study has demonstrated that biologically active food supplement extracts significantly reduced blood sugar. A standardized food-grade supplement with such efficacy may offer safety advantages compared with prescription medications.

\section{Disclosure}

Dr Vinod Podichetty is a consultant to NaturEra LLC. The other authors report no conflicts of interest in this work.

\section{References}

1. Centers for Disease Control and Prevention. National diabetes fact sheet: general information and national estimates on diabetes in the United States, 2007. Atlanta, GA. US Department of Health and Human Services, Centers for Disease Control and Prevention; 2008.

2. American Diabetes Association. Diabetes statistics. http://www.diabetes. org/diabetes-basics/diabetes-statistics/. Accessed March 3, 2011.

3. King H, Aubert RE, Herman WH. Global burden of diabetes, 1995-2025: prevalence, numerical estimates, and projections. Diabetes Care. 1998;21:1414-1431.

4. Wild S, Roglic G, Green A, et al. Global prevalence of diabetes: estimates for the year 2000 and projections for 2030. Diabetes Care. 2004;27:1047-1053.

5. Krentz AJ, Bailey CJ. Oral antidiabetic agents: current role in type 2 diabetes mellitus. Drugs. 2005;65:385-411.

6. Morphy R, Kay C, Rankovic Z. From magic bullets to designed multiple ligands. Drug Discovery Today. 2004;9:641-651.

7. Keith CT, Borisy AA, Stockwell BR. Multicomponent therapeutics for networked systems. Nat Rev Drug Discov. 2005;4(1):71-78.

8. Li Y, Huang TH, Yamahara J. Salacia root, a unique Ayurvedic medicine, meets multiple targets in diabetes and obesity. Life Sciences. 2008;82:1045-1049.

9. Sauvaire Y, Petit P, Broca C, et al. 4-hydroxyisoleucine: a novel amino acid potentiator of insulin secretion. Diabetes. 1998;47:206-210.

10. Drucker DJ. Glucagon-like peptides. Diabetes. 1998;47:159-169.

11. Jackson J, Bessler R. Clinical pharmacology of sulfonylurea hypoglycemic agents. Drugs. 1981;22:211-245.

12. Jennings A, Wilson R, Ward J. Symptomatic hypoglycemia in NIDDM patients treated with oral hypoglycemic agents. Diabetes Care. 1989;12: 203-208.

13. De Fronzo RA. The triumvirate: B cell, muscle, liver: a collusion responsible for NIDDM. Diabetes. 1988;37:667-687.

14. Kahn SE, Porte D. Islet dysfunction in non-insulin-dependent diabetes mellitus. Am J Med. 1988;85(5A):4-8.

15. Pfeifer MA, Halter JB, Porte D. Insulin secretion in diabetes mellitus. Am J Med. 1981;70:579-588.

Nutrition and Dietary Supplements

\section{Publish your work in this journal}

Nutrition and Dietary Supplements is an international, peer-reviewed, open access journal focusing on research into nutritional requirements in health and disease, impact on metabolism and the identification and optimal use of dietary strategies and supplements necessary for normal growth and development. The journal welcomes papers covering
16. Cerasi E, Luft R, Efendic S. Decreased sensitivity of the pancreatic beta-cells to glucose in prediabetic and diabetic subjects: a glucose dose response study. Diabetes. 1972;21:224-234.

17. Horwich TB, Fonarow GC. Glucose, obesity, metabolic syndrome, and diabetes relevance to incidence of heart failure. J Am Coll Cardiol. 2010;55(4):283-293.

18. Blum K, Chen TJH, Meshkin B, et al. Genotrim, a DNA-customized nutrigenomic product, targets genetic factors of obesity: Hypothesizing a dopamine-glucose correlation demonstrating reward deficiency syndrome (RDS). Medical Hypotheses. 2007;68:844-852.

19. American Diabetes Association. Standards of medical care in diabetes, 2009. Diabetes Care. 2009;32:S13-S61.

20. Valette G, Sauvaire Y, Beccou JC, Ribes G. Hypocholesterolaemic effect of fenugreek seeds in dogs. Athersclerosis. 1984;50:105-111.

21. Raghuram TC, Sharma RD, Sivakumar B, Sahay BK. Effect of fenugreek seeds on intravenous glucose disposition in non-insulin dependent diabetic patients. Phytother Res. 1994;8:83-86.

22. Mang B, Wolters M, Schmitt B, et al. Effects of a cinnamon extract on plasma glucose, $\mathrm{HbA}$, and serum lipids in diabetes mellitus type 2 . Eur J Clin Invest. 2006;36:340-344.

23. Khan A, Safdar M, Ali Khan MM, et al. Cinnamon improves glucose and lipids of people with type 2 diabetes. Diabetes Care. 2003;26: 3215-3218.

24. Kaur GJ, Arora DS. Antibacterial and phytochemical screening of Anethum graveolens, Foeniculum vulgare and Trachyspermum ammi. BMC Complement Altern Med. 2009;9:30.

25. Alarcon-Aguilar FJ, Roman-Ramos R, Flores-Saenz JL, Aguirre-Garcia F. Investigation on the hypoglycaemic effects of extracts of four Mexican medicinal plants in normal and alloxan-diabetic mice. Phytother Res. 2002;16:383-386.

26. Giannouli AL, Kintzios SE. Essential oils of Salvia spp: examples of intraspecific and seasonal variation sage. The Genus Salvia. Kintzios SE, editor. Amsterdam: Harwood Academic Publishers; 2000:69-80.

27. Baricevic D, Bartol T. The biological/pharmacological activity of the Salvia genus sage. The Genus Salvia. Kintzios SE, editor. Amsterdam: Harwood Academic Publishers; 2000:143-184.

28. Lima CF, Azevedo MF, Araujo R, et al. Metformin-like effect of Salvia officinalis (common sage): is it useful in diabetes prevention? Br J Nutr. 2006;96:326-333.

29. Imparl-Radosevich J, Deas S, Polansky MM, et al. Regulation of phosphorylase phosphatase (PTP-1) and insulin receptor kinase by fractions from cinnamon: implications for cinnamon regulation of insulin signaling. Horm Res. 1998;50:177-182.

30. Jarvill-Taylor KJ, Anderson RA, Graves DJ. A hydroxychalcone derived from cinnamon functions as a mimetic for insulin in 3T3-L1 adipocytes. J Am Coll Nutr. 2001;20:327-336.

31. Hagander B, Asp NG, Efendić S, et al. Dietary fiber decreases fasting blood glucose levels and plasma LDL concentration in noninsulindependent diabetes mellitus patients. Am J Clin Nutr. 1988;47: 852-858.

32. Sharma RD, Raghuram TC, Rao NS. Effect of fenugreek seeds on blood glucose and serum lipids in type I diabetes. Eur J Clin Nutr. 1990;44: 301-306.

33. Kibbe AH, editor. Handbook of Pharmaceutical Excipients. 3rd ed. Washington, DC and London, UK: American Pharmaceutical Association and Pharmaceutical Press; 2000.

\section{Dovepress}

original research, basic science, clinical \& epidemiological studies, reviews and evaluations, guidelines, expert opinion and commentary, case reports and extended reports. The manuscript management system is completely online and includes a very quick and fair peer-review system, which is all easy to use. 